\title{
Effect of Mental Stress on $R$ Wave Amplitude of the Electrocardiogram in Young Healthy Male Subjects
}

\author{
Yoshitaka Dor, M.D., Toyokazu Yoshida, M.D., \\ Tadayuki Hiroki, M.D., and Kikuo Arakawa, M.D.
}

\section{SUMmaRY}

The electrocardiographic effects of mental arithmetic stress were studied in 19 young, healthy male subjects. Blood pressure was measured by the cuff method before and during mental stress and electrocardiogram $\left(\mathrm{V}_{5}\right)$ was monitored and recorded continuously throughout the study using a computerized ECG monitoring system.

Heart rate increased from $65.8 \pm 7.0$ (mean \pm standard deviation) to $76.7 \pm 9.9$ beats $/ \mathrm{min}(\mathrm{p}<0.001)$. Systolic blood pressure rose from $122.7 \pm 9.6$ to $129.1 \pm 11.7 \mathrm{mmHg}(\mathrm{p}<0.05)$, diastolic blood pressure from $76.2 \pm 8.8$ to $83.0 \pm 11.0 \mathrm{mmHg}(\mathrm{p}<0.001)$, and mean blood pressure from $91.7 \pm 7.9$ to $98.5 \pm 10.1 \mathrm{mmHg}$ $(\mathrm{p}<0.001)$. These changes were all statistically significant, $R$ wave amplitude decreased significantly from $18.6 \pm 6.9$ to $17.0 \pm$ $6.5 \mathrm{~mm}$ for the group $(\mathrm{p}<0.001)$. No changes in the ST segment were observed; ST depression decreased from $0.56 \pm 0.47$ to $0.54 \pm$ $0.43 \mathrm{~mm}$ (N.S.) and ST slope from $0.87 \pm 0.59$ to $0.77 \pm 0.63 \mathrm{~mm} /$ $\sec$ (N.S.).

Thus it is apparent that mental stress reduced $\mathrm{R}$ wave amplitude without causing ST segment changes in young, healthy subjects. The mechanism and clinical implications are discussed.

\section{Additional Indexing Words:}

Mental arithmetic stress $\mathrm{R}$ wave amplitude

\footnotetext{
$\mathrm{R}^{\mathrm{n}}$ ECENTLY, there has been increasing interest in the evaluation of not only the ST segment, but also $\mathrm{R}$ wave amplitude during physical exercise testing as an indicator of cardiac status, ${ }^{1-5)}$ and many hypotheses have been proposed for the mechanism causing changes in this parameter. ${ }^{61-10}$ ) Although it has been reported that mental stress affects the ST-T wave ${ }^{11)}$ probably through an adrenergic mechanism, ${ }^{12)}$ changes in the $\mathrm{R}$ wave during

From the Second Department of Internal Medicine, Fukuoka University School of Medicine, Fukuoka 814, Japan.

Received for publication December 31, 1981.

Manuscript revised March 18, 1982.
} 
mental stress are not well described. We have attempted in this study to evaluate the effect of mental stress (mental arithmetic) on $R$ wave amplitude in young, healthy male subjects.

\section{Metrods}

Nineteen young healthy men, 18 physicians, and 1 technician in our hospital, aged 22-34 (mean 28.9) years were studied. A computer assisted system for exercise (CASE, Marquette Electronics, Inc, Milwaukee, Wisconsin) was used to monitor and record the EGG throughout the study. Analog-to-digital conversion at 4-msec sampling intervals with 12 bit precision, wave recognition, and measurements of ST depression and its slope were performed using a Digital Equipment Corporation LSI-11 computer with an accuracy within $0.1 \mathrm{~mm}$. Three automatically averaged QRS complexes, each of which represented an average of 25 consecutive QRS complexes, were measured manually and averaged to eliminate any respiratory variation of $R$ wave amplitude, such that a change of more than $0.5 \mathrm{~mm}$ in amplitude was significant. After stabilization of blood pressure in the supine position, the standard 12 leads were recorded and continuous monitoring of lead $\mathrm{V}_{5}$ was started. The monitored EGG was recorded at every 25 beats thereafter. Both heart rate, calculated from the $R-R$ interval, and depression and slope of the ST segment were printed at $1 \mathrm{~min}$ intervals. After at least 3 averaged QRS complexes were recorded, each subject was challenged to solve as many mental arithmetic problems as possible within $3 \mathrm{~min}$ while in the supine position. During this period he was stimulated with a clicking metronome and by one of our staff members telling him the time remaining. Immediately after $3 \mathrm{~min}$ of mental arithmetic, blood pressure was measured by the auscultatory method and mean blood pressure calculated by the conventional formula: (systolic blood pressure-diastolic blood pressure) $/ 3+$ diastolic blood pressure. All variables such as heart rate, blood pressure, $R$ wave amplitude, and depression and slope of ST segment, both at rest and during mental arithmetic, were compared. A paired t test was used for the statistical analysis.

\section{Results}

All hemodynamic and ECG data at rest and during mental arithmetic are given in Tables I and II. A positive correlation was found between changes in blood pressure and those in heart rate as seen in Fig. 1, indicating that they increased proportionately during the stress. Heart rate increased 


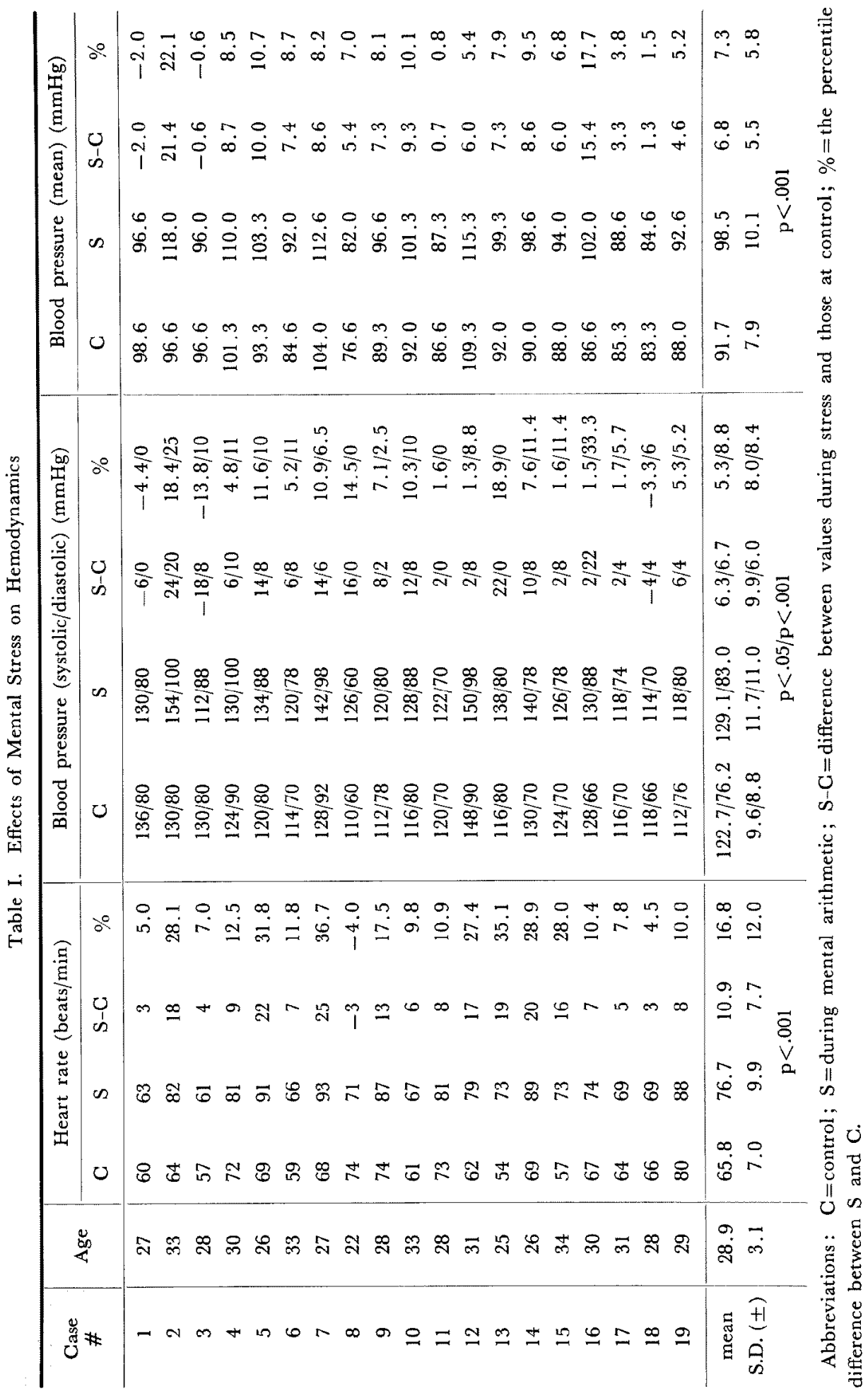




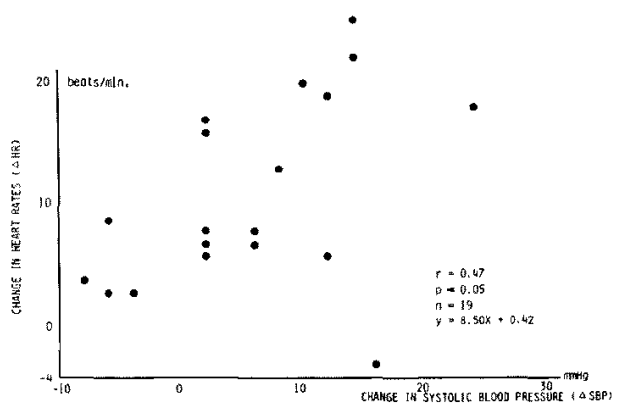

Fig. 1. Mental arithmetic induced changes in heart rate are plotted against changes in systolic blood pressure. There is a positive correlation between the two $(r=0.47, p<0.05)$, indicating that both of them increased proportionately during the stress.
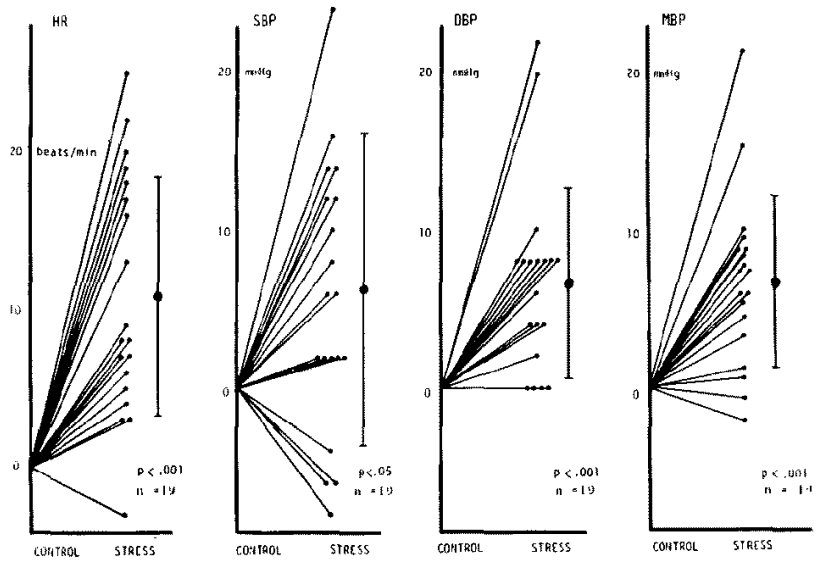

Fig. 2. Changes in hemodynamics induced by mental arithmetic. Heart rate (HR), systolic blood pressure (SBP), diastolic blood pressure (DBP), and mean blood pressure (MBP) are plotted. Values are presented as the mean \pm SD. All of these variables demonstrate a statistically significant increase with mental stress.

by $10.9 \pm 7.7$ beats $/ \mathrm{min}$, from a mean of 65.8 to 76.7 beats $/ \mathrm{min}$ for the group $(\mathrm{p}<0.001)$, systolic blood pressure by $6.3 \pm 9.9 \mathrm{mmHg}$ from 122.7 to 129.1 $\mathrm{mmHg}(\mathrm{p}<0.05)$, diastolic blood pressure by $6.7 \pm 6.0 \mathrm{mmHg}$ from 76.2 to $83.0 \mathrm{mmHg}(\mathrm{p}<0.001)$, and mean blood pressure by $6.8 \pm 5.5 \mathrm{mmHg}$ from 91.7 to $98.5 \mathrm{mmHg}(\mathrm{p}<0.001)$. Fig. 2 demonstrates these changes.

Changes in $\mathrm{R}$ wave amplitude and ST segment from the control are shown in Fig. 3. $R$ wave amplitude decreased by $1.6 \pm 1.4 \mathrm{~mm}$ from a mean of 18.59 to $16.95 \mathrm{~mm}(\mathrm{p}<0.001)$. ST segment did not show any consistent changes in depth or slope, depression changing from 0.56 to 0.54 (N. S.) and slope from 0.87 to $0.77 \mathrm{~mm} / \mathrm{sec}$ (N. S.). The change in $\mathrm{R}$ wave amplitude 

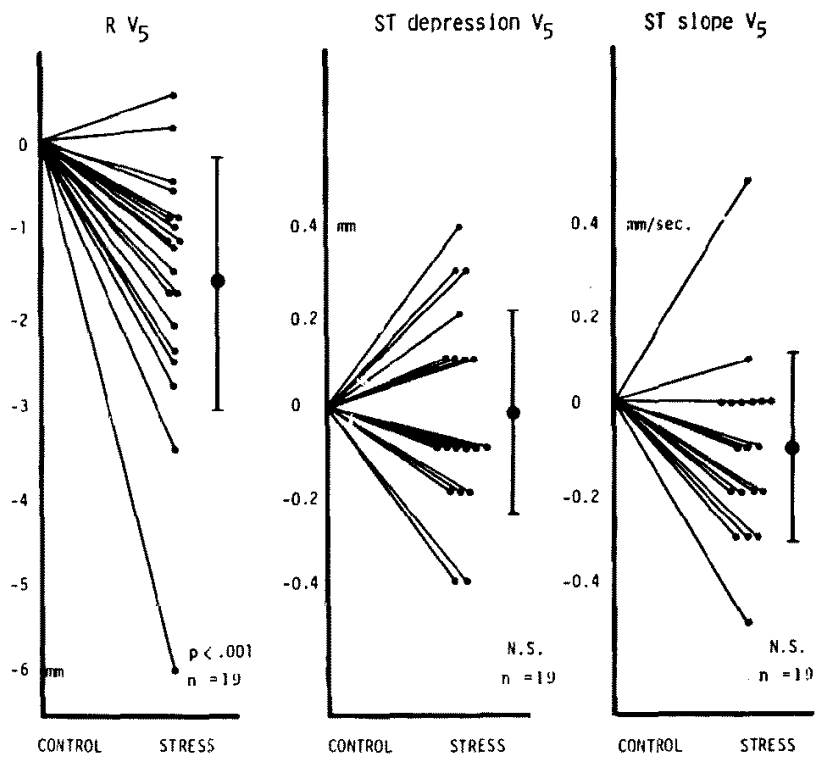

Fig. 3. Changes in $R$ wave amplitude in lead $V_{5}\left(R V_{5}\right)$, ST segment depression ( $\mathrm{STV}_{5}$ depression), and its slope $\left(\mathrm{STV}_{5}\right.$ slope) from the control are shown. Values are presented as the mean $\pm S D$. $R$ wave amplitude decreased significantly during mental stress $(\mathrm{p}<0.001)$. ST segment did not reveal any consistent change in depression or slope.

versus the change in heart rate, and the change in $\mathrm{R}$ wave amplitude versus the change in systolic blood pressure are illustrated in the scattergrams of Figs. 4 and 5, respectively. There were no correlations in either case.

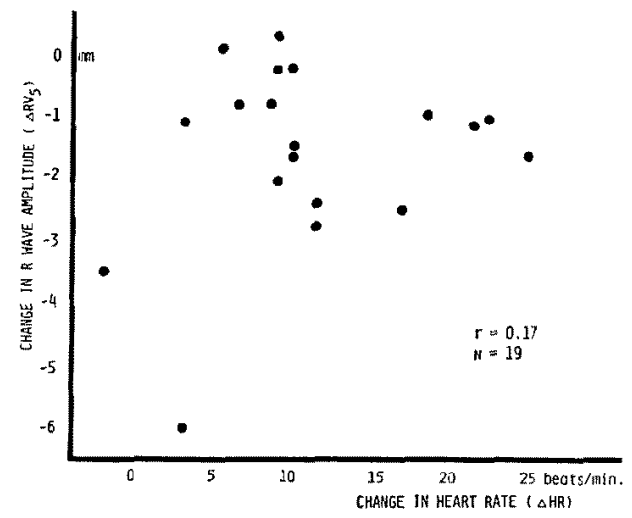

Fig. 4. Changes in $\mathrm{R}$ wave amplitude are plotted against changes in heart rate. There is no correlation between the two, suggesting that heart rate is not a major factor in reduction of $R$ wave amplitude during mental stress. 


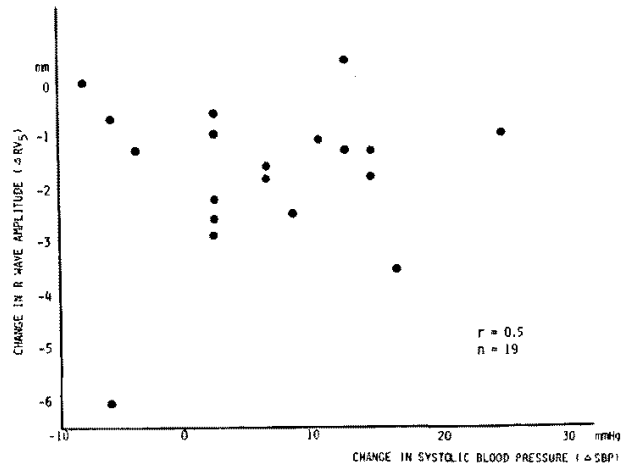

Fig. 5. The changes in $\mathrm{R}$ wave amplitude versus the changes in systolic blood pressure are illustrated. There is no correlation between the two, suggesting blood pressure is not a major determinant in reduction of $R$ wave amplitude during mental stress.

\section{Discussion}

Psychological or mental stress is known to play a role in the pathogenesis of cardiovascular disease and hypertension. ${ }^{13), 14}$ Stressful situations have becn said to cause acute changes in hemodynamics, and may precipitate angina pectoris if there is underlying coronary heart disease. ${ }^{14}$ ) Robinson reported that the hemodynamic changes during mental stress were comparable to those caused by light to moderate exercise, and indeed, an anginal episode was provoked in 1 patient with mental stress. ${ }^{15)}$ Hemodynamic changes caused by mental stress are reportedly characterized by increase in cardiac output, heart rate, blood pressure and myocardial contractility, and by a decrease in total peripheral resistance. ${ }^{12)}$ This is probably through an adrenergic mechanism, since plasma catecholamine levels increase during mental stress, ${ }^{16), 17)}$ and the effects are preventable by $\beta$-adrenergic blockade. ${ }^{18 \text { ) }}$

In the present study, mental stress was induced by 3 min of mental arithmetic. The hemodynamic changes were quite similar to those reported by Falkner ${ }^{19)}$ and Bassan. ${ }^{20)}$ Falkner et al reported increases in systolic blood pressure $(5.9 \mathrm{mmHg})$, diastolic pressure $(3.5 \mathrm{mmHg})$, and heart rate $(7.1$ beats/min) following $10 \mathrm{~min}$ of mental stress. Blood pressure values, obtained indirectly, were almost the same as those obtained $3 \mathrm{~min}$ after the initiation of mental stress in their study. Bassan et al had their subjects perform mental arithmetic for 2 to $2.5 \mathrm{~min}$, and measured arterial blood pressure directly from a radial or femoral artery. They found that systolic blood pressure increased by $19.3 \mathrm{mmHg}$, diastolic blood pressure by $7.1 \mathrm{mmHg}$, and heart rate by 11.6 beats/min. The higher baseline systolic blood pressure and the greater increase seen during mental stress compared with our findings as well 
as Falkner's were probably due to the differences in age of subjects and method of determining blood pressure. Bassan's subjects were older (mean age of 53.1 years) than ours (28.9 years), who were older than Falkner's (14.8 years). Based on these findings, $3 \mathrm{~min}$ seems to be a reasonable time period for evaluating the effects of mental stress on the cardiovascular system.

Physical exercise testing, such as Master's two-step testing and treadmill exercise testing, has been commonly performed to evaluate coronary heart disease in clinical cardiology, ${ }^{21)}$ and ST segment depression has been an important criterion in detecting myocardial ischemia. ${ }^{22)}$ Recently, it has been noticed that either augmentation or no change in $\mathrm{R}$ wave amplitude during physical exercise testing correlates with left ventricular dysfunction in ischemic heart disease. ${ }^{1,5)}$ It has also been reported that the sensitivity and specificity of physical exercise testing in the diagnosis of coronary heart disease are increased if both ST depression and $\mathrm{R}$ wave changes are taken into account at the same time. ${ }^{2)}$ Simoons et al demonstrated a decrease in $\mathrm{R}$ wave amplitude during exercise in healthy men and speculated that the mechanism was a reduction in the blood conductivity and intracardiac volume (Brody effect). ${ }^{61,23)}$ Other possible mechanisms are the effect of heart rate, hyperventilation, shift in position of body or electrode, displacement of the heart from chest wall, myocardial ischemia, and increased myocardial contractility itself. ${ }^{7)-10), 24), 25)}$ In our study, there was poor correlation between changes in $\mathrm{R}$ wave amplitude and heart rate, and also between changes in $\mathrm{R}$ wave amplitude and blood pressure suggesting that neither heart rate nor blood pressure were major determinants of $R$ wave amplitude reduction. It is unlikely that there was any effect due to a shift in body or electrode position, because the subjects were kept in the supine position throughout the study. Hyperventilation was not observed in any subjects. The most likely mechanism to account for the reduction in $\mathrm{R}$ wave amplitude seen in the present study seems to be enhanced myocardial contractility and increased cardiac output, which have been reported to occur during mental arithmetic, ${ }^{12)}$ and which would reduce cardiac volume and decrease $R$ wave amplitude through the Brody effect or Battler's hypothesis, i.e., increased distance between the heart and anterior chest wall. Echocardiography, which would provide information about cardiac dimensions or volume, might be helpful in confirming these mechanisms.

Neither degree of depression nor slope of the ST segment changed in any consistent manner. This is in agreement with Guazzi's study, which showed no ST segment depression during mental stress in healthy subjects. ${ }^{12)}$ However, they did observe inverted $\mathrm{T}$ waves in hyperkinetic patients and enhanced $\mathrm{T}$ wave inversion and $\mathrm{ST}$ segment depression in ischemic and hy- 
pertensive patients.

$R$ wave amplitude in $V_{5}$ is also important as a voltage criterion for left ventricular hypertrophy. ${ }^{26)}$ Since it may be greatly influenced by the patient's psychological condition, as seen in this study (maximum $6 \mathrm{~mm}$ decrease in case \#1), it is important to bear in mind that there is always the possibility that left ventricular hypertrophy may be overlooked in borderline cases on the first visit to the clinic, and to keep patients relaxed during ECG recording.

\section{REFERENCES}

1. Bonoris PE, Greenberg PS, Castellanet MJ, Ellestad MH: Significance of changes in R wave amplitude during treadmill stress testing. Angiographic correlation. Am J Cardiol 41: 846, 1978

2. Bonoris PE, Greenberg PS, Christison GW, Castellanet MJ, Ellestad MH: Evaluation of R wave amplitude changes versus ST-segment depression in stress testing. Circulation 57: 904, 1978

3. Uhl GS, Hopkirk JAC: Analysis of exercise-induced R wave amplitude changes in detection of coronary artery disease in asymptomatic men with left bundle branch block. Am J Cardiol 44: 1247,1979

4. Caprio L, Cuomo S, Bellotti P, Adamo B, Postiglione M, Vigorito C, Rengo F: R wave amplitude changes during stress testing. Comparison with ST segment depression and angiographic correlation. Am Heart J $99: 413,1980$

5. Berman JL, Wynne J, Cohn PF: Multiple-lead QRS changes with exercise testing. Diagnostic value and hemodynamic implications. Circulation 61: 53, 1980

6. Brody DA: A theoretical analysis of intracavitary blood mass influence on the heart-lead relationship. Circulat Res 4: 731, 1956

7. Rieckkinen $H$, Rautaharju P: Body position, electrode level, and respiration effects on the Frank lead electrocardiogram. Circulation 53: 40, 1976

8. Shapiro W, Berson AS, Pipberger HV: Differences between supine and sitting Frank-lead electrocardiograms. J Electrocardiology 9: 303, 1976

9. Carbonin P, Gennaro MD, Valle R, Beranbei R, Habed A: Intracellular calcium and electrogram in ischemic isolated rat heart. Am J Physiol 239: H380, 1980

10. Battler A, Froelicher VF, Gallagher KP, Kumada T, McKown D, Kemper WS, Ross J Jr: Effects of changes in ventricular size on regional and surface QRS amplitudes in the conscious dog. Circulation 62: 174, 1980

11. Ruttkay-Nedecky I: Effect of emotional stress on cardiac repolarization vectors. Adv Cardiol 21: 284, 1978

12. Guazzi MD, Magrini F, Olivari MT, Polese A, Fiorentini C: Influences of the adrenergic nervous system on the repolarization phase of the electrocardiogram. Angiology 29:617, 1978

13. Buell JC, Eliot RS: Psychosocial and behavioral influences in the pathogenesis of acquired cardiovascular disease. Am Heart J 100: 723, 1980

14. Harlan WR: Physical and psychosocial stress and the cardiovascular system. Circulation 63: 266A, 1981

15. Robinson BF: Relation of heart rate and systolic blood pressure to the onset of pain in angina pectoris. Circulation 35: 1073, 1967

16. Januszewicz W, Sznajderman M, Wocial B, Feltynowski $T$, Klonowicz T: The effect of mental stress on catecholamines, their metabolites and plasma renin activity in patients with es- 
sential hypertension and in healthy subjects. Clin Sci 57: 229s, 1979

17. Dimsdale JE, Moss J: Plasma catecholamines in stress and exercise. JAMA 243: 340,1980

18. Bergamaschi M, Longoni AM: Cardiovascular events in anxiety. Experimental studies in the conscious dog. Am Heart J 86: 385, 1973

19. Falkner B, Onesti G, Angelakos ET, Fernandes M, Langman C: Cardiovascular response to mental stress in normal adolescents with hypertensive parents. Hemodynamics and mental stress in adolescents. Hypertension 1: 23, 1979

20. Bassan MM, Marcus HS, Ganz W: The effect of mild-to-moderate mental stress on coronary hemodynamics in patients with coronary artery disease. Circulation 62: 939, 1980

21. Bruce RA, Hornsten TR: Exercise stress testing in evaluation of patients with ischemic heart disease. Prog Cardiovasc Dis $11: 371,1969$

22. Sanmarco ME, Pontius S, Selvester RH: Abnormal blood pressure response and marked ischemic ST-segment depression as predictors of severe coronary artery disease. Circulation 61: 572,1980

23. Simoons ML, Hugenholtz PG: Gradual changes of ECG waveform during and after exercise in normal subjects. Circulation 52: 570, 1975

24. Wagner $\mathrm{S}$, Cohn $\mathrm{K}$, Selzer $\mathrm{A}$ : Unreliability of exercise-induced $\mathrm{R}$ wave changes as indexes of coronary artery disease. Am J Cardiol 44: 1241, 1979

25. Manoach M, Grosman E, Varon D, Gitter S: QRS amplitude changes during heart filling and digitalization. Am Heart J $83: 292,1972$

26. Friedman HH: Diagnostic Electrocardiography and Vectorcardiography, McGraw-Hill Book Co, New York, p 129, 1971 